\title{
Non-venereally transmitted 'endemic' syphilis in Vienna
}

\author{
ANTON LUGER \\ Department of Dermatology, Vienna City-Lainz Hospital, Austria
}

There were several outbreaks of non-venereal 'endemic' syphilis among children in Europe up to the beginning of the 20th century, and the disease is still found in some developing countries (Grin, 1962; Guthe and Luger, 1957, 1965; Luger, 1958, 1959a, 1964). Besides its original epidemiological sense the term 'endemic syphilis' has also acquired a nosological connotation, and the condition is now characterized by certain epidemiological as well as clinical traits, namely non-venereal transmission in childhood, early skin eruptions followed by late destructive gummatous lesions, absence of other systemic manifestations, and absence of congenital syphilis. Mucous patches as well as condylomata lata prevail during the secondary period. The main criterion, however, is non-venereal transmission among children (Guthe and Luger, 1965).

Three cases of non-venereal 'endemic' syphilis affecting three children in one family were observed in Vienna in 1968. The history was almost the same in all three patients who had each suffered from alopecia for several months. One had had a rash 2 months before, diagnosed as rubella. All three had complained of pains in the mouth and had received non-specific local therapy. They were eventually seen in the outpatient clinic of the Dermatological Department of the Vienna City-Lainz Hospital.

Case 1, an 8-year old girl, had lentil-sized, slightly raised bluish-white patches on the mucous membranes at the angles of the mouth. The rest of the oral cavity and the pharynx were free from lesions. Two embossed, solid, brownish-red, superficially eroded moist condylomata lata, each the size of a pea, were localized in the perianal region. The scalp showed a diffuse patchy specific alopecia. There was generalized slight enlargement of the lymph nodes.

Received for publication March 29, 1972

Head of the Department of Dermatology and Director of the Vienna City-Lainz Hospital, Wolkersbergenstrasse 1, A 1130, Wien, Austria
Case 2, a 5-year old boy, had several lentil-sized, bluishwhite opalescent lesions on the mucous membrane of the cheeks, on the left margin of the tongue, and sublingually on the same side. Two brownish-red, elevated, velvety, superficially eroded, round condylomata lata $10 \mathrm{~mm}$. in diameter, were found close to the anus. The hair on the scalp was thin and the lymph nodes were enlarged.

Case 3, a 3-year old boy, also had lentil-sized, slightly elevated bluish-white lesions on the mucous membrane at the angles of the mouth. One bean-sized condyloma latum was found close to the anus. The scalp showed a diffuse patchy specific alopecia. The lymph nodes were enlarged.

\section{Results of tests}

In all three cases many $T$. pallidum were found on darkfield examination of serum obtained from the condylomata. The serum reagin tests (Wassermann, Meinicke, Müller, Kahn, VDRL) were reactive. A quantitative VDRL test showed a titre of $1: 16$ in Cases 2 and 3, and of $1: 32$ in Case 1. The FTA-200 test was reactive in all three patients.

\section{Treatment}

Each of the children was admitted to hospital and received intramuscular injections of 500,000 units aqueous procaine penicillin $G$ daily for 21 days. Protracted daily therapy in hospital was necessary for environmental reasons.

The clinical signs regressed rapidly, the mucous patches disappearing within a few days, and the condylomata lata by the end of the 21 days of treatment. The hair began to grow again and after a few months no signs of alopecia could be seen.

\section{Follow-up period}

A steady decrease in the VDRL test titres was observed and reactivity ceased by February, 1969, 5 months after the termination of treatment. All lipoid antigen tests remained non-reactive. The treponemal antigen tests (TPI, FTA-ABS, and TPHA) were still reactive at the last examination in June, 1972.

\section{Epidemiological investigation and discussion}

Non-venereal transmission of syphilis to and among children is very rare in 'civilized' communities. The 
infection cannot be transmitted from the host to another recipient except under circumstances which enable the inoculum to be transferred in a moist state. Such transfer is hardly possible among persons with a reasonable standard of hygiene, as treponemes are very fragile outside the host organism, and do not survive slight rises in temperature (Turner and Hollander, 1957), desiccation, or even otherwise inadequate washing (Brit. med. F., 1956).

These observations were confirmed by investigations in the remote swamps and forests of the Sudanese border of Ethiopia, where the Baro River approaches the White Nile (Luger, 1959b). Two tribes inhabit this territory, the Anuaks and the Nuers. The Anuaks are a settled race, living on the shores of the rivers in huts. They bathe frequently and are generally much cleaner than the nomadic Nuers, who belong to the Nilotic ethnic group. Endemic treponematoses, mainly yaws, occur widely among the Nuers, but are rarely found among the Anuaks.

Other investigations have shown that unhygienic living habits and particularly bad housing conditions are essential factors in the spread of non-venereal syphilis (Grin, 1953, 1960, 1962; Guthe and Luger, 1957, 1965; Luger, 1958, 1959a, 1964; Luger, Mandil, and Trudeau, 1958). Poor hygiene favoured the outbreaks of endemic infections after the second world war, as described by Kozlowski and Srokowska (1952) in Poland, by Féjer (1948) in Hungary, by Eisenberg, Plötke, and Baker (1949) in the slums of Chicago, and by Grin $(1953,1960,1962)$ in the rural areas of Bosnia. Rajam and Rangiah (1952) found an endemic type of syphilis among infected children in the crowded slums of Madras. Investigations in Syria 15 years ago (Luger, 1958, 1964; Luger and others, 1958) showed that the disease was less common among the settled population, who lived in mud-brick houses, than among the nomads and semi-nomads, who lived in tents or shelters made of branches.

\section{PRESENT CASES}

Because living standards have been shown by many observers to affect the spread of endemic syphilis, the housing and living conditions of the Viennese family were studied. They were found to be living in one room in an asylum for the homeless, the household consisting of the parents of the three infected children and their 9-month-old brother, with the mother's brother, his wife, and a 3-week-old baby. Surprisingly, none of these other members had any signs of syphilis and they remained non-reactive to serological tests during an observation period of 6 months (Fig. 1).

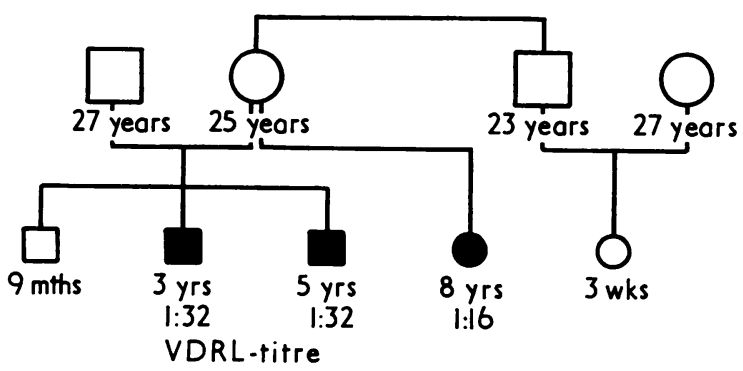

FIG. 1 Persons who lived with the infected children in the same room (Black: infected. White: clinically and serologically without evidence of syphilis)

The source of infection had therefore to be found outside the family. The possibility of transmission through sexual contact by a pervert or by assault was kept in mind, but this was excluded by a careful study of all the circumstances and by questioning the family members and all possible contacts, who were examined clinically and serologically. The investigations were performed in cooperation with qualified physicians of the V.D. section of the Government Health Services, social workers, and the officials of the home. All the findings indicated that the children could not have contracted the disease by venereal contact, and a non-venereal infection, favoured by crowded housing conditions and by poor hygiene, had therefore to be assumed.

The home belongs to the City of Vienna and is administered by Government officials. It consists of 72 rooms for families and six dormitories. At the time of the investigations, in September, 1968, 355 persons-176 adults and 179 children-were living there. The asylum had been built in 1908 to provide emergency quarters for homeless persons or families, and had been used as a barracks during the second world war. The number of persons housed there fluctuated widely and had fallen from 355 in September, 1968, to 192 by January, 1969 (Fig. 2).

\section{TOTAL INHABITANTS}

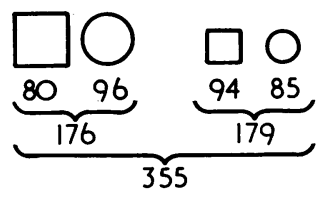

SEPTEMBER, 1968

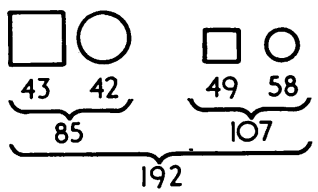

JANUARY, 1969

FIG. 2 Total occupancy of asylum for homeless in 1968 and 1969 
The construction was antiquated, but the house appeared to be clean and in relatively good repair, and was well organized and administered. A plan is given in Fig. 3.

The situation on the second floor of the left wing at the time of the investigations carried out in September, 1968, is shown in Fig. 3. Seven rooms housed forty persons-seventeen adults and 23 children. The most crowded room was that where the patients lived; four adults and five children occupied a space of 16 sq. metres. The warden did not normally permit the admission of more than one family to a room, but the mother's brother and his wife had registered as visitors and their continued presence was then tolerated because the birth of their daughter was imminent.

The occupants of this floor had at their disposal communal facilities for cooking (two gas stoves with ovens), a wash-room with five hand-basins, and a toilet with two water closets.

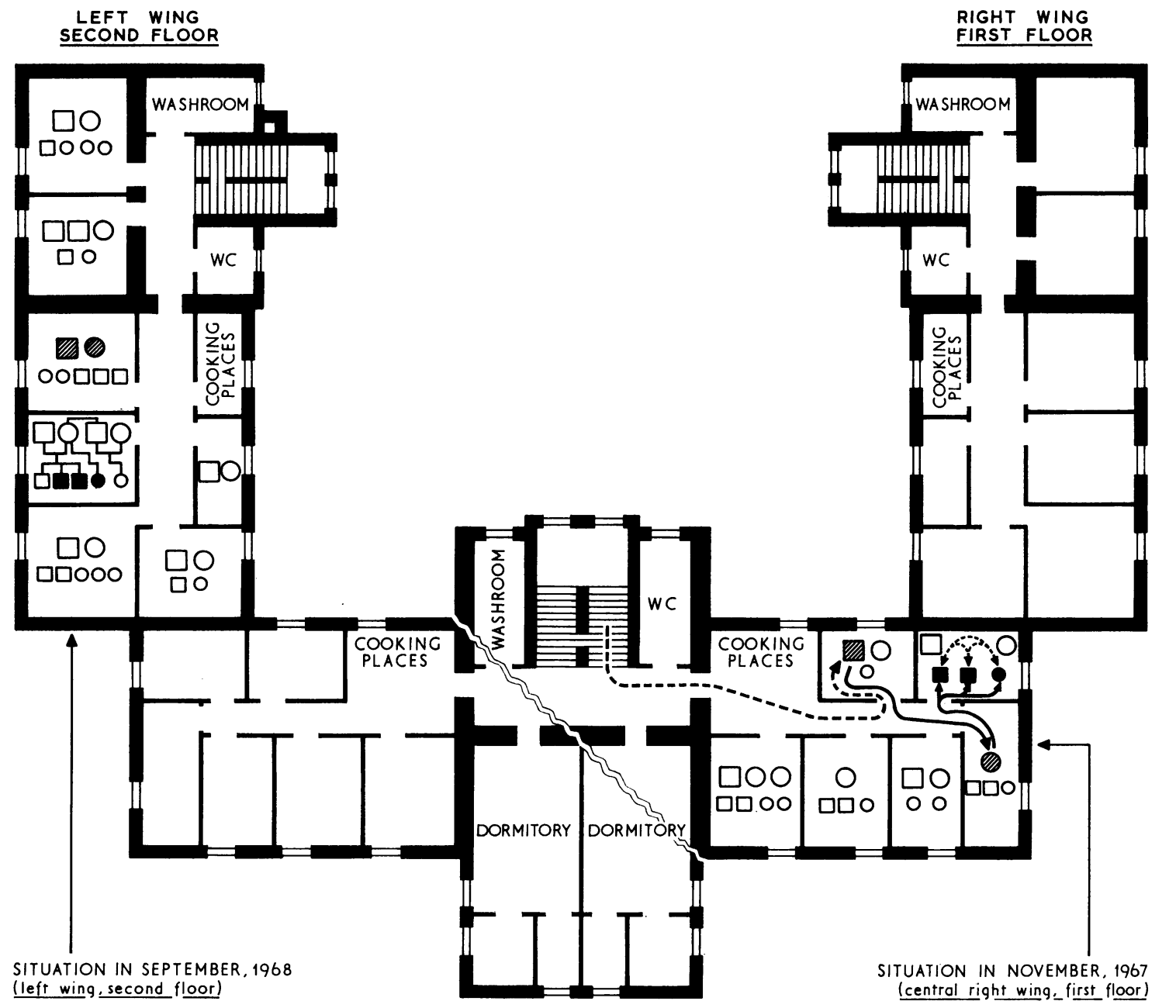

FIG. 3 Plan of asylum for homeless, showing location of infected children at time of infection in November, 1967, and at time of diagnosis in September, 1968

Black: persons who had early infectious manifestations

Shaded: persons who were clinically and serologically free from syphilitic infection after penicillin treatment of early syphilis in previous year

White: healthy persons 
In view of the crowded living conditions, all persons who lived on the same floor as the patients were examined for infection. Possible contacts also included children at a school and kindergarten which the syphilitic children attended until their infection was discovered. Clinical and serological examination of all these contacts or suspected contacts was organized by the public health authorities but no case of syphilis was found.

The clinical state of the patients, especially the presence of alopecia and of condylomata lata, suggested that the infection had occurred some time before. It has been shown (Luger and Ebner, 1963) that reactivity in the serological tests lasts comparatively longer after treatment in patients suffering from this type of lesion than in those with other syphilitic manifestations. Syphilitic alopecia is a symptom which usually appears at some time late in the secondary stage. The date of infection was estimated as between September, 1967, and March, 1968, according to the clinical histories and our general knowledge of the manifestations of endemic syphilis.

Further investigations of the source of the infection brought to light that the couple living in the adjoining room (with their five children) had both been treated one year previously at the Department of Dermatology of the Vienna City-Lainz Hospital for early infectious syphilis; the man had a chancre on the penis and his wife had moist genital papules. It was at first assumed that the three children under investigation had been infected by these people, but it was found that the children had been living in another wing and on another floor at the estimated time of infection.

From an examination of the housing situation in November, 1967, it was possible to reconstruct the probable chain of infection. At that time an asocial young man, of no fixed address, was living in his grandmother's room in the asylum together with a child who stayed with them from time to time. This room was situated on the first floor of the central part of the right wing (Fig. 3). The young man had contracted syphilis outside the building and had later infected a woman who lived in the asylum in a room close to that of his grandmother. This woman frequently associated with the three children, particularly the girl (Case 1), and often visited the room where the children and their parents were then living (Fig. 3). The infected man and woman had received treatment at that time (November to December, 1967), and the children who lived with the infected woman were kept under observation but proved to be non-infected, but the children in the neighbouring rooms were not included in the examinations as they were not considered to be in danger of infection. Nevertheless, the infection was apparently transmitted from the woman to the three children. No other means of infection could have remained a secret in view of the overcrowding and lack of privacy. It is possible that not all three children contracted the disease from the woman, but that one child (possibly the girl) became infected by the woman and transmitted the infection by non-venereal contact to her two brothers.

The general standard of hygiene in the asylum and in the school and kindergarten attended by the children was apparently sufficiently high to prevent any further spread of infection. An unannounced inspection of the rooms supported this assumption. The families kept their toilet articles separately and obviously made use of the facilities for washing, as they appeared to be clean and did not give the impression that they were irresponsible people.

The family of the three patients did not live in poverty except for the overcrowding. Their room was furnished with a refrigerator, television set, record player, and two radios, all of good quality. The furniture was clean and well-kept. The adults were not asocial persons. The two men, who were in regular employment, took care of their families, attended regularly for examination during the observation period, and took presents to the three children while they were kept in hospital. This outbreak of disease stimulated them to seek proper accommodation and within 8 weeks of the diagnosis of syphilis they had moved into a rented flat.

The occurrence of 'endemic' syphilis in Vienna is remarkable for three reasons:

(1) The non-venereal transmission of syphilis is very rare among children in countries with a high standard of 'civilization' (cleanliness and medical care);

(2) The patients were under medical treatment for some months, including that of a dermatologist, before the disease was diagnosed. Syphilis must therefore always be included in the differential diagnosis of lesions on the skin and mucous membranes;

(3) The sociological findings illustrate the mentality of a type of person who cannot be considered as primarily asocial. The parents gave priority to consumer goods, providing convenience and some prestige, to the neglect of their housing requirements.

\section{Summary}

The outstanding feature of 'endemic' syphilis is its non-venereal transmission among children. Such transmission is very rare in a civilized community, 
but may be favoured by poor hygiene and living conditions.

Three children with syphilitic alopecia, mucous patches, and condylomata lata were seen in Vienna in September, 1968. They were living at the time in one room with four adults and two other children. The infection, which cleared quickly after penicillin treatment, was probably caught from a female neighbour. No serological reactivity remained 5 months after the termination of treatment. Contact investigations of the family, the immediate neighbours, and children in the school and kindergarten attended by the patients did not reveal any further cases of syphilis, suggesting a good standard of hygiene in their environment.

The rarity of non-venereal 'endemic' syphilis in a civilized community is emphasized by the fact that the three children were treated by general practitioners and also by a dermatologist for some time before a diagnosis was made.

\section{Referen ces}

Brit. med. F. (1956) 2, 1070

Eisenberg, H., Plötke, F., and BAKeR, A. H. (1949) f. vener. Dis. Inform., 30, 7

FéJER, E. (1948) Orv. Lapja, 4, 616. Quoted by T. Guthe and R. R. Willcox (1954) in 'Treponematoses, a World Problem'. World Health Organization, Geneva

GriN, E. I. (1953) 'Epidemiology and Control of Endemic Syphilis'. WHO Monograph Series No. 11. (Chron. WHO, 8, 37)

- (1960) 'Proc. XI Int. Congr. Dermatology, Stockholm, 1957', ed. S. Hellerström, K. Wikström, and A. M. Hellerström, vol. 3, p. 914

- (1962) Transactions and 48th Report of the St. Fohns Hospital Dermatological Society, pp. 11-26

Guthe, T., and Luger, A. (1957) Dermatologica (Basel), 115, 248

- (1965) 'The Control of Endemic Syphilis of Childhood'. INT/VDT/203.65

Kozlowski, J., and Srokowska, R. (1952) Przegl. Derm., 39 (n.s.2), 589
LUGER, A. (1958) Derm. Wschr., 137, 25

(1959a) Wien. klin. Wschr., 71, 253

- (1959b) Assignment Report Venereal Diseases Control Project, Ethiopia, EM/VD/30, pp. 1-43. WHO, Geneva

(1964) Arch. klin. exp. Derm., 219, 211

and EBNER, H. (1963) Wien. klin. Wschr., 75, 629

-, Mandil, A., and Trudeau, R. A. (1958) Int. $\mathcal{F}$. proph. Med., 2, 1

Rajam, R. V., and Rangiah, P. N. (1952) 'A Study of Acquired Infectious Syphilis in Childhood', WHO/ VD/79. WHO, Geneva

TuRner, T. B., and Hollander, D. H. (1957) 'Biology of the Treponematoses'. WHO Monograph Series No. 35, Geneva

Syphilis 'endémique' transmise par voie non vénérienne à Vienne

\section{SOMMAIRE}

La caractéristique principale de la syphilis 'endémique' est sa transmission non vénérienne chez les enfants. Un tel mode de transmission est très rare dans les milieux civilisés mais elle peut être rendue possible par des conditions de vie ou d'hygiène défectueuses.

A Vienne, en septembre 1968, on a observé trois enfants présentant une alopécie syphilitique, des plaques muqueuses et des condylomes. Ils vivaient à ce moment dans une seule pièce avec 4 adultes et 2 autres enfants. La maladie, qui guérit rapidement après un traitement par la pénicilline, avait été probablement communiquée par une femme du voisinage. Cing mois après la fin du traitement, la sérologie se maintint négative. Les recherches sur les membres de la famille, les voisins immédiats, les enfants de l'école ou du jardin d'enfants que fréquentaient les malades ne permirent pas de découvrir d'autres cas de syphilis, ceci suggérant que l'hygiène était satisfaisante chez ces contacts.

La rareté de la syphilis 'endémique' non vénérienne en milieu civilisé apparaît bien dans le fait que les trois enfants furent soignés par des practiciens de médecine générale et aussi par un dermatologiste pendant quelques temps avant que le diagnostic ne fut posé. 